\title{
SYNKRETISME: EN ANALYSE AF ILLEGITIME BLANDINGER OG TREDJE-IDENTITETER
}

\author{
Anita Maria Leopold
}

\section{Indledning}

Kulturmøde og religiøs identitet i forandring berører problemstillinger vedrørende religiøse 'blandingsformer', som også kan betegnes som de 'tredje-identiteter', fordi de markerer forskellen til de mere traditionelle identiteter, der konfronteres i et kulturmøde. Disse religiøse 'blandingsformer' er bedre kendt under begrebet synkretisme og hører til en af religionsvidenskabens mere kontroversielle kategorier. Set ud fra et forskningshistorisk perspektiv har begrebet medvirket til at forme modsætningsfyldte positioner inden for både religionsforskningen og især inden for studiet af kristendommen og andre religioner i berøring med denne.

I et etymologisk perspektiv vidner begrebet synkretismes skiftende fortolkninger om, at en betydning ikke er konstant, men afhængig af konteksten. Især har teologiens tvetydige forhold til synkretisme påvirket religionsforskningens problematisering af begrebet. Det er blandt andet blevet påpeget, at synkretisme er et mangelfuldt begreb, fordi det typisk repræsenterer den udenforståendes synsvinkel på de 'andres’ religion frem for den indforståedes religiøse selvforståelse (Baird 1971). Men med henvisning til termens historie illustrerer begrebet synkretisme ikke et fænomen, som man direkte kan pege på i verden. Synkretisme er snarere en 'samlebetegnelse', der henviser til en særlig type relation mellem forskelligartede fænomener. ${ }^{1}$ Derfor hverken beskriver eller forklarer begrebet noget i sig selv, men det vedrører en række problemstillinger omkring relationer mellem religioner, religiøse elementer og religiøse identiteter. I stedet for at afskaffe kategorien synkretisme, som det er blevet anbefalet inden for visse kredse af religionsforskningen, foreslår jeg, at man bør undersøge også de problematiske definitioner af begrebet op igennem dets historie, idet det vil ikke blot give os et større overblik over 'problemstillingen synkretisme', men generelt set vil det give indsigt i 'problemstillingen religion- og kultur-møde'. Herunder vil også et studie af motiver for dannelse af religiøse identiteter i en kulturmødesituation kunne indgå. I det følgende vil jeg komme med eksempler fra den kristne missionshistorie, som illustrerer, hvorledes

\footnotetext{
${ }^{1}$ Jeg skelner mellem synkretisme som ‘fænomen’ og som ‘begreb’. Fænomenet synkretisme henviser i min forståelse ganske enkelt til det objekt vi studerer: dvs. en konstatering af at generelt set indoptager religioner elementer fra andre religioner og/eller sekulære systemer, og at dette kan føre til, at nye religiøse former eller betydninger opstår. Begrebet, derimod, refererer til de perspektiver vi tillægger objektet: dvs. det er en samlebetegnelse, hvori også forskellige videnskabelige og religiøse diskurser indgår i et forsøg på at definere fænomenet og dets sociale, politiske eller historiske relationer.
} 
begrebet synkretisme indirekte er indgået både som et 'politisk' og 'mentalt' motiv for dannelsen af religiøse identiteter.

\section{2. 'Religionsblanderi' og kristen mission}

Det er blevet fremhævet, at synkretisme først og fremmest er et kristent missionsproblem. Det skyldes blandt andet missionens vekslende politik mht. 'religions- og kultur-blanderi' igennem tiderne, der dels har været præget af skiftende definitioner af kristen 'identitet' ${ }^{2}$ dels af forholdet til 'de fremmede' som målgruppe for missionen.

Begrebet synkretisme optræder første gang hos Plutark, som bruger termen synkretismos til at illustrere, hvorledes kretenserne på trods af interne stridigheder forenede sig, når en ydre fjende truede. Etymologisk set er synkretismos betegnelsen for kretenserne eller kretismos, der betyder noget i retning af 'sådan som kretenserne gør'. I Plutarks anvendelse får begrebet både en forsonende og en politisk undertone, idet forsoningen i mødet med en fælles fjende medfører en nedtoning af indre forskelle til samfundets bedste. Men Plutarks fredsstiftende fortolkning er blevet kritiseret for ikke at svare til den senere kristne reference til synkerannumi = 'at blande' eller 'at sammenblande', der i betydningen 'illegitime blandinger' blev brugt polemisk af protestantiske teologer i en intern strid i det 16. og 17. århundrede. Årsagen til denne 'synkretistiske strid' var en følge af visse teologers forsøg på at bistå en økumenisk forening af de reformerte kirkers og den katolske kirkes konfessionelle modsætninger. Det var således Erasmus af Rotterdam (1469-1536) og Georg Calixtus (1586-1656) fra Helmstad, der brugte termen synkretizein i lighed med Plutark i betydningen af 'at forene' eller 'at kombinere', som et billede på økumenisk forsoning. Men disse fortalere for en forenet kristendom blev i stedet anklaget for at være 'synkretister' $\mathrm{i}$ betydningen synkerannumi, dvs. illegitime blandinger. Som en følge af dette har kirkens syn på synkretisme også påvirket kristen missions 'selvforståelse' samt målgruppens egen 'selvforståelse'. Dette samspil har medvirket til dannelsen af nye religiøse identiteter i et kulturmøde.

Spørgsmålet om synkretisme udgør så tidligt som i det 16. århundrede, en vigtig faktor i den kristen missionspolitik. Det var i den mere tolerante og forsonende ånd, at jesuitterne i det 16. århundrede tilpassede kristendommen til japansk kultur for at lokke den japanske adelsstand til at konvertere. Også i Kina tillod jesuitterne at konfucianske ritualer og forfadertilbedelse indgik sammen med den kristne lære som et led i hvervningen af proselytter (McManners 1992, 317). I 1622 besluttede man i Rom som et led i denne tolerante missions politik at rekruttere gejstlige fra missions landenes

\footnotetext{
2 Identitet betyder ganske enkelt 'det samme som'. Også i min anvendelse af begrebet. Denne noget forenklede definition henviser til det faktum, at på trods af at en religiøs bevægelse som kristendommen (og andre i lighed med denne) består af mange forskelligartede enkelt-individer med forskelligartede 'identiteter', så er disse samlede under en fælles religiøs identitet (en kanon) formet ved og reguleret af et sæt leveregler, rituelle forskrifter og trosforestillinger. I teorien betyder det, at man er forenet ved det 'samme som' alle andre af samme tro uanset nationalitet, køn, etnisk oprindelse og politisk orientering.
} 
indfødte befolkninger, samtidig med at man indførte et dekret om, at de indfødtes traditioner skulle respekteres (McManners 1992, 320). Men i begyndelsen af det 18. århundrede var der kræfter inden for kirken, der begyndte at modarbejde jesuitterne, som de beskyldte for føre en alt for afslappet missionspolitik. Følgen på dette blev, at Rom strammede reglerne for missionen (s. 327f) og i højere grad end før fordømte synkretisme. Denne tvetydige holdning til begrebet er bevaret i den romersk-katolske kirke helt frem til vor tid, som man kan læse det i et dekret af pave Paul 6. udstedt i 1965 ved 'Det andet Vatikankoncil'. Pavens udtalelser vidner her på en og samme tid om en tolerant missionspolitik og en fordømmelse af synkretisme, idet han på den ene side opfordrer missionslandenes unge kirker til at 'låne' fra deres respektive kulturelle baggrunde og inkorporere disse i en kristen livsførelse, og på den anden side fordømmer synkretisme som falsk partikularisme, der bør udelukkes fra en kristen livsførelse. Dette dilemma mellem kulturelle lån og synkretisme, som kommer til udtryk i pavens ord, er både en erkendelse af en pluralisme, som mødet mellem den kristne mission og den ikke-kristne verden har medført, og et forsøg på at kontrollere denne pluralisme. Der skelnes imellem 'at låne’ (borrow) som et legalt led i tilegnelsen (adaption) af kristendommen og 'synkretisme' som en falsk partikularisme. Dvs. at i denne forbindelse identificeres begrebet synkretisme med det, som ligger uden for kristen livsførelse eller 'identitet'. Deraf kan man slutte, at en undersøgelse af identitet som middel og reaktion på de politiske omstændigheder ved et givent kulturmøde er på sin plads - også når talen falder på synkretisme.

Således medvirkede den kristne mission i Nordamerika (den protestantiske såvel som den katolske) i sine anstrengelser på at omvende de amerikanske indianere og afrikanske slaver til at forstærke væksten af nye og indbyrdes forskellige religiøse såvel som etniske identiteter. Det var kun relativt få amerikanske indianere, der konverterede til kristendommen og de, der gjorde, skabte en 'synkretistisk' blanding af traditionel forfaderkult og kristen tro som blev afvist som hedenskab af missionærerne (Marty 1992, 401). Anderledes stod det til, da de amerikanske slaveejere endelig begyndte at interessere sig for deres slavers sjæle og som følge deraf organiserede metodist og baptistmenigheder for slaverne, der resulterede i nye afrikansk-inspirerede former for metodist og baptist-menigheder (s. 402). De sorte kirkers etnisk-prægede kristendom blev netop tolereret, fordi det kunne bevises, at også i religiøs henseende var de sorte ifølge gældende race-teorier den hvide mand underlegen (s. 407). De amerikanske eksempler afslører således både ‘accept og forbud’ mht. synkretisme alt afhængig af kulturmødets karakter. Mht. til de amerikanske indianere havde mødet med de hvide indvandrere været så voldeligt, at man i stedet for at integrere dem i ‘det hvide Amerika' holdt dem isoleret i reservater. Derfor var der ingen politisk interesse i at tillade 'synkretisme' eller etniske 'lån’ som middel til deres integration. Derimod var situationen med de sorte amerikanere anderledes, fordi de som slaver allerede var blevet integreret i 'den hvide familie'. Det er grunden til, at en 'afro-kristen synkretisme' bedre kunne tolereres som et skridt på vejen mod integration i 'det hvide samfund' (Herskovits 1958, xxiiff og Stewart 1995, 17-22). 


\section{De tredje identiteter - et økumenisk alternativ}

Følgerne af den kristne missions restriktive og noget tvetydige politik mht. inkorporeringen af fremmede elementer i kristendommen kan spores i programmet for Ecumenical Association of Third World Theologians (EATWOT). Hensigten med organisationen er at samle 'den tredje verdens' teologer i et økumenisk fællesskab, der skal udvikle en anden teologisk praksis end den herskende europæiske form, og som bedre passer til de forskellige kulturelle og etniske baggrunde, som deltagerne hver især repræsenterer. Ifølge James H. Cone, et medlem af EATWOT, er den kulturelle og politiske bagage en nødvendig del af den kristne trosopfattelse: “The liberating character of their spirituality can be seen in the way their faith in God evolves out of their cultural and political aspirations” (Torres 1985, 101). Indbefattet i EATWOTs dagsorden er en omformulering af det kristne budskab til en 'befrielsesteologi', der sigter mod at genvinde værdierne fra de traditionelle kulturelle og religiøse udgangspunkter:

Thus the struggle against cultural imperialism is an intrinsic aspect of all liberation struggles. Asian, Africans, and the indigenous peoples of Latin America and elsewhere seek to recover values in their traditional religions and cultures denigrated by christianization and westianization. Feminists seek an alternative culture to those values defined by a masculine definition of normative humanity. Both of these struggles - to recover indigenous cultures and to create new ones - converge on a number of common themes ... Ultimately the cultural aspect of liberation theology is a struggle for values that enhance rather than truncate human life. Christianity itself is renewed in the process ... and restored as a message of liberation (s. 185f).

Kravet fra disse tredjeverdens økumenikere om en alternativ form for teologi afspejler ikke i lighed med Calixtus ønsket om en forenet kristendom. Tværtimod opfordrer de til en accept af kristendomme i pluralis. Begrebet synkretisme henviser i den forbindelse ikke så meget til 'forsoning af forskelle’ men snarere til en legitimering af sådanne. EATWOTs 'befrielsesteologi' udtrykker en måde at overleve på i en splittet verden og rummer især ønsket om en legitimering af religiøse såvel som kulturelle 'blandingsformer'. I begrebet 'befrielse' ligger mere end blot et krav til den kristne øvrighed om kirkernes accept af ellers anonyme og forskelligartede etniske, kulturelle og politiske 'identiteter'. Snarere formulerer EATWOTs medlemmer et alternativt grundlag for at kalde sig kristen- en slags ‘tredje-identitet', der skal være med til at sikre grundlaget for en ny kristen betydningsstruktur, der rummer mange forskelligartede identiteter og fortolkninger af kristendommen. Bemærk at begrebet 'tredjeverdens teologer' ikke udelukkende er en geografisk bestemmelse, idet 'feministisk teologi' også hører ind under begrebet, fordi det først og fremmest skal ses i modsætning til 'første verdensteologer' og deres mere 'eurocentriske' teologi.

Ved at inddrage begrebet 'tredje-identiteter' i overvejelserne af EATWOTs økumeniske program har jeg villet vise, hvorledes dette program ikke blot skal ses som 
resultatet af en syntese af forskelle eller ligheder, men at identitetspluralismen, som kommer til udtryk i programmet, i sig selv repræsenterer den nye struktur, som organisationen ønsker gennemført inden for kristendommen. Begrebet 'tredje-identiteter' påpeger tillige en anden 'synkretistisk struktur' end den, der blot bygger på assimilering eller forsoning af forskelle (som beskrevet af Plutark og Calixtus). I stedet peges der på, at innovationer er mere sammenlignelige med 'knopskydninger' end med simple sammenblandinger.

\section{Synkretisme- en problematisk kategori}

Med disse eksempler fra den kristne missionshistorie og en moderne økumenisk organisation har jeg ønsket at vise, hvorledes begrebet synkretisme på forskellig vis, såvel negativt som positivt, er indgået som et identitetsskabende fænomen i kristendommen på trods af en antisynkretistisk grundholdning. Det forhold har, som jeg indledte med at antyde, endvidere haft indflydelse på religionsforskningens tilbageholdenhed over for begrebet.

Da Robert Baird i sin tid foreslog at forkaste kategorien, fordi den var mangelfuld og brugt på selvmodsigende måder (1971, 143), var det især Hendrik Kraemer (professor i religionshistorie i Leiden og aktiv i missionsbevægelsen), som han anklagede for at bruge termen normativt til at skelne mellem kristendommen og fremmede religioner (s.144 og 146-148). Kraemer søgte da også at vise, hvorledes synkretisme først og fremmest er et ikke-kristent fænomen karakteristisk for især orientalske religioner. Ifølge Kraemer har orientalske religioner modsat kristendommen en pragmatisk og 'medfødt evne' for synkretisme (Kraemer 1938, 202). ${ }^{3}$ Bairds og generelt set religionsvidenskabens indvendinger imod Kraemers definition skyldes den værdibestemmende karakter og fundamentale væsensforskel, som han indsætter i begrebet. Men ifølge Baird er kategorien ikke blot normativt mistænkelig, men også intetsigende, fordi alle religioner i deres grundform kan siges at være 'en synkretisme'. 4 Derfor hævder han at den ikke formår at beskrive noget specifikt om religion, men udelukkende den kendsgerning, at lån, blandingsformer og påvirkninger historisk set er uundgåelige og universelle (Baird 1971, 146).

Mht. sidstnævnte påstand er jeg uenig med Baird, fordi der ikke nødvendigvis skal bestå et 1:1-forhold mellem kategori og fænomen. Begrebet eller kategorien synkretisme er snarere en samlebetegnelse for en række forskelligartede fænomener samt teoretiske diskurser og analyser, der blandt andet vedrører fra kulturmødeproblematikker og religion i bevægelse, hvorunder synkretisme som identitetsskabende fænomen rangerer. Nok er kategorien problematisk men ikke nødvendigvis intetsigende, fordi den

\footnotetext{
3 'The pragmatist attitude in religion and the natural innate syncretistic apprehension (min kursivering) dominate the religious scene in all naturalist religions, whether in the past or in the present' (s. 201-2).

${ }^{4}$ Det var Geradus van der Leeuw, der ud fra et citat af Joachim Wach fastslog: "Every religion, therefore, has its own previous history and is to a certain extend a 'syncretism””, 1938, s. 609.
} 
henviser til noget generelt. Både kristendommens tvetydige anvendelse af begrebet og Kraemers typologi vidner om, at hverken begrebet eller fænomenet uden videre kan bortforklares, hvorfor man ikke bør afvise at bruge det på sine undersøgelser af religionskulturmøder. Tværtimod, vil jeg hævde, er der god grund til at antage, at begrebet kan bruges til at pejle sig ind på nogle fundamentale forskelligheder i religioner, der mere præcist kommer til udtryk, når de konfronteres med hinanden - eller sammenlignes i religionsvidenskaben.

\section{Teorien om divergerende religiøse modi}

Skal vi så tage Kraemers påstand om en væsensforskel mellem kristendom og ikkekristen religion for pålydende? Jeg vil hævde både ja og nej! Men ifølge Harvey Whitehouses teori om divergerende religiøse modi ("divergent modes of religiosity", Whitehouse 2000) er der basis for at opstille en videnskabeligt objektiv model (i modsætning til Kraemers teologisk-normative typologi), der beskriver forskellige kognitive såvel som sociale og politiske måder at organisere religion på, og som kan have betydning for, hvordan vi forstår synkretisme, især mht. forholdet mellem den missionerende kristendom og andre religioner. Med baggrund i sine studier i Melanesien har Whitehouse udarbejdet en model, der kombinerer og forbinder nogle af kognitionsvidenskabens teorier om hukommelse med spørgsmål vedrørende forskellige religiøse former for politisk organisation og transmission. Dette bruges som argument for at skelne mellem to meget forskellige modi af religiøs aktivitet:

(i) a doctrinal mode of religiosity in which the emphasis is on explicit, standardized beliefs, repetitive sermonizing and ritual, wide dissemination of the tradition, and the institutionalization of religious authorities as guardians of orthodoxy; (ii) an imagistic mode of religiosity in which emotionally and sensually laden imagery is evoked in rare and climatic rituals, triggering intensely personalized experiences and lines of interpretation, and establishing enduring cohesion within small communities of participants. Some religions emphasize one mode of religiosity over the other. But it is more common for both modes to be present in any given religion (Whitehouse 2001).

Kraemer og andre (bl.a. Baird) kan have ret i deres konstatering af, at synkretisme først og fremmest præsenterer et problem for kristen mission. Dette skyldes ifølge Whitehouse, at kravet til doktrinær ortodoksi på den ene side og mission på den anden side gør den kristne lære mere udsat for forandringer i et transmissionsforløb. Whitehouse karakteriserer udbredelsen af læren som en proces, gennem hvilke særlige, absolutte og forudindtagede vilkår accepteres:

The persuasiveness of Christianity rests to some extent on the plausibility of its absolute presuppositions and the comprehensiveness with which it supplies answers to all possible questions that connect them ... Faith may spring from other sources and the way it is codified may be taken for granted, but without its system of interlocking rhetoric, 
Christianity could not exist or, rather, would be a very different kind of religion (2000, 36).

Måden at kodificere og transmittere doktrinen på er ikke uvæsentlig i en forståelse af, hvorfor kristendommen har udviklet sig til en succesrig verdensreligion samtidig med, at den har været primus motor for mange 'synkretistiske' processer og stridigheder. Whitehouse argumenterer for, at indlæringsprocessen for en doktrinær religiøs modus grundlæggende bygger på en 'semantisk hukommelses-type' (semantic memory), der kan karakteriseres ved, at den former 'basisskemaer' for hukommelsen af en mere generel karakter, som fx hvordan man opfører sig på en restaurant, hos en frisør eller går i kirke (s. 5-9). ${ }^{5}$ Formen for kodificering i doktrinære religioner, der bygger på semantisk hukommelse er grundlæggende sproglig og rutinepræget indlæring, som det kommer til udtryk i hellige skrifter, gudstjenester, teologiske diskussioner m.m. Det er ifølge Whitehouse medvirkende til, at det kan lade sig gøre at danne religiøse samfund i lighed med kristendommen, der består af store grupper af anonyme, uidentificerbare tilhængere (s. 9 og s. 40). Men begrænsningen er derimod, at der ikke er plads til ret mange individuelle og nytænkende fortolkninger. Innovationer, hvad pavens dekret beskrevet ovenfor også vidner om, skal legitimeres af den gejstlige øvrighed, før de kan kaldes kristne. De retningslinier, som den kristne mission har dikteret som en fælles kristen tro og livsførelse, og som også berører udformningen af identitet, har derfor været anledning til, at spændinger opstod i mødet med andre religiøse former. Således også mht. de før-kristne stammesamfund i Papua Ny Guinea, som ifølge Whitehouse ikke kendte til en fælles religiøs kanon endsige et større fælles socialt netværk. Derimod bestod de af små og spredte samfund med meget forskellige religiøse traditioner og kun en lille grad af interaktion. Fælles for melanesisk religion var før mødet med den kristne mission, at den var 'imagistisk' og ganske ubekendt med den doktrinære religiøsitet, som missionærerne præsenterede melaneserne for (Whitehouse 2000, $18 \mathrm{f}$ ). ${ }^{6}$

Whitehouse beskriver den imagistisk religiøse modus som kodificeret ved initiationsriter, der benytter sig af ikonografiske fremstillinger frem for sproglige, og som direkte udsætter initianderne for enten fysiske pinsler eller andre stærke og uvante følelsesmæssige sanseindtryk. Disse 'rites of terror' (s. 23-33), ${ }^{7}$ der regionalt set er

\footnotetext{
5 "Thus, semantic memory consist of the common denominators of a series of episodic memories, along with invented details that fit with the schema but are not experienced as authentic or definite recollections of individual episodes”, Whitehouse 2000, 7. Whitehouse har sin teori om 'semantic memory' fra bl.a. G. Cohen og E. Tulving ibid..

${ }^{6}$ Jævnført med Kraemers påstand om orientalske religioners 'pragmatisme’ nævner Whitehouse, at man typisk for antropologien har overtaget begrebet 'Melanesian pragmatism' fra missionærerne, fordi det i begyndelsen var de materielle goder fremfor den kristne lære, der trak de indfødte til missionen. Men som Whitehouse understreger, var det snarere fordi den doktinære form var aldeles ukendt og underlig for melaneserne, op.cit., s. 37f.

7 Whitehouse skriver vedrørende 'rites of terror': "This combination of cognitive and emotional crises produces long-lasting and poignant memories ... Now, the political implications of initiatory traumas reside
} 
fragmenterede rituelle traditioner, er indkodet i, hvad han beskriver som 'episodisk hukommelse' eller 'autobiografisk hukommelse' (s. 7-9), hvilket gør, at stammesamfundenes religiøse forestillinger i Papua Ny Guinea er rigt varierede med en tendens til en individuel 'dynamisk kreativitet' frem for ensrettede trosforestillinger (s. 1 og s. 15).

Kraemers påstand om visse ikke-kristne religioners 'medfødte evne’ for synkretisme, afkræftes af Whitehouses undersøgelse. Begrundelsen finder Whitehouse i, at det høje emotionelle niveau, som ritualerne producerer, er indkodet i autobiografisk langtidshukommelse. Derfor er hukommelsessvigt ikke udbredt på trods af, at der kan gå en generation imellem at ritualerne udføres (s. $102 \mathrm{f}$ ). Han noterer endvidere, at forandringer eller innovationer pga. hukommelses-svigt kun synes at have meget begrænsede indvirkninger på kulturens eller gruppens ideologiske grundform (s. 108 f). Dette skyldes ifølge Whitehouse, at der ikke hersker det samme krav om et ensrettet trossystem som i en doktrinær religiøsitet. Det er kun mht. de rituelle fremgangsmåder, at der principielt set er overensstemmelse - ikke mht. en bestemt 'betydning' (Whitehouse 2001, 11). ${ }^{8}$ Derimod aktiveres en spontan eksegetisk refleksion som resultat af de stærke følelsesmæssige oplevelser, initianden gennemgår under ritualet, der giver anledning til meget personlige fortolkninger: "producing a sense of multivalence and multivocality of religious imagery, experienced as personal unmediated inspiration" (2001, 10f). Men religiøs 'multivocality' giver ikke nødvendigvis anledning til en større grad af synkretisme, især ikke i relation til de melanesiske ritualer, hvor den religiøse metaforik er indbygget i ikonografien i form af en 'analogisk kodning', der har til hensigt at åbenbare eksklusiv viden om tilværelsen, som før initiationen ikke var tilgængelig for initianten (Whitehouse 2000, 88-93). Den type af analogisk kodning, som Whitehouse beskriver, afslører kort fortalt forbindelserne mellem fænomener, som kun tilsyneladende er forskellige, men er identiske under overfladen. Det kan naturligvis være indirekte anledning til 'lån', men de er i langt mindre grad en direkte årsag til innovationer i forhold til systemets grundform, end det er tilfældet med en 'digital kodning' (fx. ondt/godt, himmel/helvede se s. 93ff), som vi blandt andet kender fra kristen metaforik. En sådan sproglig og digital kodning har, pga. sine begrænsende modsætninger, en tendens til at provokere større spændinger og konflikter, især hvis der sås tvivl om begrænsningerne.

Ifølge Whitehouses undersøgelser af kristne bevægelser i Papua, Ny Guinea, er det påfaldende, at synkretisme først og fremmest kan spores her og ikke så meget inden for

partly in the nature of the moving and long-lasting memories that they evoke, and partly in the contrived circumstances of transmission. The religious understandings cultivated in initiation ritual derive from collective performances, and can only be disseminated among neighbouring groups, or through the displacement of whole populations”, 2000, 30f.

${ }^{8}$ Projektet British Academy Network Project on 'Modes of religiosity', som er blevet bevilliget til Harvey Whitehouse, indbefatter bl.a. en konference om 'Modes of Religiosity' for religionshistorikere, historikere og arkæologer i August 2002, som jeg her henviser til, er skrevet til den anledning. 
traditionel melanesisk religion. Blandt andet viser det sig at være en reaktion på den rutineprægede doktrinære religiøsitet i form af, hvad han betegner som 'splinter groups':

The terms 'break away' and ‘splinter groups' suggest a radical division between mainstream and local religious ideology but this is seldom the case. What crucially takes place in these splinter groups is not so much a reformulation of othodox dogma but a recodification of it. The central principles of mainstream ideology are recast in iconic imagery $(2000,129)$.

Det er nærliggende at sammenligne EATWOT med en form for 'splinter group', dog med den forskel, at det ville gå for vidt at beskrive deres program som specielt 'imagistisk', snarere er målsætningen for EATWOT et omformuleret 'dogme’. Derfor er det i denne sammenhæng mere nærliggende at inddrage begrebet 'church movement', som Michael A. Williams (1996) låner fra Rodney Stark til at beskrive valentinianerne i hellenistisk-romersk tid. Typisk for de valentinianske 'kirkebevægelser' var, at de i højere grad end den almene kristne bevægelse var tilpasset den hellenistisk-romerske socio-kulturelle kontekst (s. 109 ff): “Though theologically there were striking differences between this schismatic movement and groups such as the Valentinians, both seem to have splintered off the 'front end' of the second-century C.E. sect-church spectrum” (s. 112). Men hvad enten, at vi henviser til ‘splinter group’ eller ‘church movement', mener jeg med disse eksempler fra kristen missionshistorie, at kunne påvise, at tendensen til 'synkretisme' vil være større inden for doktrinære systemer i lighed med kristendommen, fordi de teologiske eller eksegetiske uoverensstemmelser er direkte medvirkende til at skabe behovet for innovationer.

\section{Konklusion}

Med hensyn til Whitehouses teoretiske model mener jeg ikke, at det er nok at forbinde spørgsmålet om innovationer til de to forskellige hukommelsestyper som nævnt ovenfor (den semantiske og den autobiografiske). Snarere finder jeg, at henvisningen til de to modsatrettede mentale kodninger, den analoge og den digitale, er lige så relevant i en undersøgelse af synkretisme. Især bør man være opmærksom på, hvornår man definerer 'en synkretisme’ ud fra et analogt eller digitalt standpunkt. Selvom det måske ligner det sædvanlige skel mellem 'insider' og 'outsider', adskiller begreberne 'analogt' og 'digitalt' sig ved, at de sagtens kan eksistere sammen inden for såvel som uden for et bestemt felt, hvad både forskningshistorien og de religiøse kilder vidner om. Derfor, hvis jeg foreløbigt skal komme med et bud på, hvorledes synkretisme fungerer i et kulturmøde som identitetsskabende fænomen, så må det være i spændingsfeltet mellem det analoge og det digitale - altså mellem det, der er 'lig med', og det, der er 'forskelligt fra'. Hermed opstår 'blandingsformer' eller snarere nye ‘knopskydninger’ i løbet af en 
tilegnelsesproces i både et mentalt og et socialt spændingsfelt. En sådan tilegnelsesproces er, i lighed med Whitehouse beskrivelse af situationen i Papua Ny Guinea, naturligvis altid afhængig af de givne politiske og kulturelle begrænsninger såvel som de kognitive mønstre. Hvad der fastsættes som legitimt eller illegitimt, må nødvendigvis også afhænge af spændingsfeltet mellem det mentale og det sociale i ethvert givent kulturmøde.

\section{Litteratur}

BAIRD, ROBERT

1971 Category Formation and the History of Religions, Haag.

ENGEL, Peter

1976 Die eine Warhrheit in der gespaltenen Christenheit. Untersuchungen zur Theologie Georg Calixts, Göttingen.

HERSKOVITS , MELVILLE

1958 The Myth of the Negro Past, sec. ed., Boston. [1941].

KRAEMER, HENDRIK

1938 The Christian Message in a Non-Christian World, New York.

LEOPOLD, ANITA, M.

2001 "The Architecture of Syncretism: A methodological illustration of the dynamics of syncretism”, Historical Reflections/Réflexions Historiques, vol. 27, no. 3, 401-23.

MARTY, MARTIN

1992 “North America”, ed., John McManners, The Oxford Illustrated History of Christianity, Oxford, 384-419.

MCMANNERS, JOHN

1992 “Enlightenment: Secular and Christian (1600-1800)”, ed., John McManners, The Oxford Illustrated History of Christianity, Oxford 267-300.

MCNEIL, JOHN THOMAS

1930 Unitive Protestantism, New York.

Pye, MiCHAEL

1971 “Syncretism and Ambiguity”, Numen 18, 83-93.

RUDOLPH, KURT

1992 "Synkretismus - Vom Theologischen Scheltwort zum Religionswissenshaftlichen Begriff ”, Geschichte \& Probleme der Religionswissenschaft, Leiden, 193-213.

STEWART, CHARLES

1995 "Relocating Syncretism in Social Science Discourse", Syncretism and the Commerce of Symbols, ed., Göran Aijmer, Göteborg, 13-37.

1994 "Syncretism as a dimension of nationalist discourse in modern Greece”, eds., C. Stewart \& R. Shaw, Syncretism/Anti-Syncretism: The Politics of Religious Synthesis, London and New York, 127-44.

TORRES, SERGIO

1985 "Preface", Doing Theology in a Divided World, eds., V. Fabella and S. Torres, Papers from the sixth International Conference of the Ecumenical Association of Third World Theologians, Maryknoll, ix-xix.

VAN DER LEEUW 
1938 Religion in Essence and Manifestation: A Study in Phenomenology, J. E. Turner, trans., London.

WhiteHOUSE, HARVEY

2000 Arguments and Icons. Divergent Modes of Religiosity, Oxford.

2001 Et udskrift fra British Academy Network Project on 'Modes of religiosity', 1-25.

\section{Summary}

On the basis of the notion of syncretism this article discusses the issues of constructing new religious identities in the history of Christian mission. 'Syncretism' represents one of the more controversial categories in the study of religion that have been exposed to solid scholarly critic, partly because of the notion's problematic situation in the history of Christian mission. In spite of the problems of definition 'syncretism' may function as a 'composite notion' to analyse 1) the scholarly discourses of the notion 2) the issues of the phenomenon concerning the formation of new religious identities that emerge from 'the blending of religion' in the encounters of cultures. But to approach or rethink the issues of the notion anew we must look for new theoretical groundings. This article suggests Harvey Whitehouse's theory of distinct modes of religiosity, an 'imagistic' and a 'doctrinal,' based on Melanesian ethnography, which combines theories on memory from the field of cognitive science with theories on the organisation of social and political systems in religion. By application of the theory to 'syncretism' identified as a type of innovation of identity, and to examples from Christian mission-history, it is suggested that the different modes of religiosity have influenced both the different forms of codification and the innovation of religious identities inside Christian communities.

Anita Maria Leopold Ph.d.-stipendiat, cand.phil. Institut for Religionsvidenskab Aarhus Universitet 

